\title{
И.А. Подюков
}

\section{КОМИ-ПЕРМЯЦКАЯ МИФОЛОГИЧЕСКАЯ ЛЕКСИКА И ФРАЗЕОЛОГИЯ КАК ОБЬЕКТ ЛЕКСИКОГРАФИЧЕСКОГО ОПИСАНИЯ ${ }^{1}$}

Представлено описание различных групп коми-пермяцкой мифологической лексики и фразеологии - номинаций мифологических персонажей и событий, мифологизированных явлений природы, названий обрядовых атрибутов и акций. В анализ включены как оригинальные, так и заимствованные мифонимыл. Свод мифологически окрашенных названий позволяет рассмотреть особенности этномышления коми-пермяков, мифологические представления которых составляют значимый элемент этнического культурного кода. Лексикографическое описание мифонимов позволит раскрыть особенности духовной культуры коми-пермяков, их культурно-языковые контакты с другими народами.

Ключевые слова: мифологическая и обрядовая лексика и фразеология, культурные заимствования, словарь, коми-пермячкий язык.

По словам Р.О. Якобсона, «язык является составной частью культуры... функционирует как ее подструктура» [1. С. 379]. Культура (в том числе и воплощённая в формах живого языка) имеет дело со знаками особой, семиотической природы, поэтому лексикографирование ее единиц имеет свою специфику. Семантика этих знаков - не номинативные значения и не оценочные характеристики, а культурные смыслы, представляющие в образной или символической форме осознание человеком окружающего мира, своего места в нём. Этнокультурные, мифологические, этнолингвистические словари способствуют выявлению многообразия этнокультурных ориентаций современного мира. Потребность в словарном описании этнокультур связана с необходимостью осознания норм, ценностей, идеалов, символов той или иной этнической группы, с решением проблем этнокультурного образования и межкультурной коммуникации. Проект словаря комипермяцкой мифологической лексики и фразеологии, разрабатываемый

\footnotetext{
${ }^{1}$ Исследование выполнено в рамках гранта РГНФ № 17-14-59001 «Фразеология коми-пермяцкого языка в контексте традиционной коми-пермяцкой культуры».
} 
в ходе этнолингвистического исследования коми-пермяцкого языка, направлен на описание самобытной культуры коми-пермяков Прикамья, представителей финно-угорской группы уральской семьи языков, в ее языковом отражении.

Мифологическая лексикография, имеющая уже достаточно богатый опыт, представлена рядом словарей, в которых для описания обрядов, обычаев и верований на равных правах использованы собственно лексикографический и энциклопедический подходы. После появления словаря Н.И. Толстого «Славянские древности» намечалась разработка аспектных этнокультурных словарей, обращенных к мифологически окрашенным аспектам традиционной народной культуры. Русские диалектные демонимы Прикамья представлены в материалах разрабатываемого Демонологического словаря Пермского края и Этнолингвистического словаря мифологических рассказов Пермского края [2. С. 15-21]. Народная хрононимика описана в этнолингвистическом словаре «Русский народный календарь» О.В. Атрошенко, Ю.А. Кривощаповой, К.В. Осиповой [3]. Словарные статьи по донской народной хрононимике и демонимике, по мифологически окрашенной фитонимике, терминологии обрядовой одежды будет содержать создаваемый «Этнолингвистический словарь донского казачества» [4. С. 129-132]. Создаются словари, иллюстрирующие особенности тюркских мифологий - «Этнолингвистический словарь татарского языка» Ф.И Салимова и Р.Ф. Салимова [5], в котором дано описание лексики обрядов, связанных с рождением ребенка, свадьбой, смертью и погребением; представляющий синтез мифологического и толкового словарей «Мифологический словарь башкирского языка» Ф.Г. Хисамитдиновой [6]. Последний содержит описание около 5000 слов и выражений, отражающих понятия и термины башкирской мифологии (имена и эпитеты мифических персонажей, названия явлений природы и стихий, растений и животных, наименования обычаев и ритуалов). Наконец, появляются проектные разработки учебного мифологического словаря [7. С. 183-187].

Наработанная практика показывает, что мифологический словарь, фиксируя следы древнего мифического мышления в языке, описывает предметы и явления фантастического и внешнего мира как культурные реалии, совмещая при этом качества энциклопедии и толкового словаря. В его состав включаются названия сакральных объектов и признаков и связанной с ними фразеологии, поверия и легенды о про- 
исхождении мифологически осмысленной реалии (растения, животного, стихии), описание магических функций и ритуальных применений их в обрядах, народной медицине и т.п. Особое внимание обращается на заглавные слова, которые выступают как маркированные в народной культуре представления и образы, как имена культурных концептов. В словаре дается не только описание толкуемой лексемы, но и структурирование соотносимых с ней культурных смыслов и круга представлений, связанных с описываемой реалией, с выполняемыми ею культурными функциями. По мысли ряда исследователей, в силу своей значимости описываемая единица для полноты интерпретации должна быть энциклопедически охарактеризована по образному основанию и соотнесена с древнейшими формами осмысления мира и представлениями, имеющими архетипическую природу [8. С. 19-22]. На основе анализа контекстов употребления данной единицы определяются функции, выполняемые ею в культуре, сами контексты сопровождаются кратким комментарием (кем, кому, в каких обстоятельствах произносятся). В словарных статьях описываются отличия этих номинаций, ситуации их применения. В словарь, следовательно, включаются такие параметры, как этимологический, фольклорный, культурологический, прагматический. Специально отмечаются основные устойчивые мотивы, сопутствующие тем или иным мифологическим персонажам, устойчивые характеристики описываемых реалий. Культурная семантика и функционирование наименования описываемой реалии иллюстрируются включенными в состав словаря текстами, а его специфика иллюстрируется аналогами и образными эквивалентами, существующими в других лингвокультурах.

В описании мифологической лексики народов коми сделаны лишь первые шаги. Объяснение мифологических понятий и имен содержится в электронной энциклопедии по мифологии коми [9]. Статьи энциклопедии посвящены персонажам, предметам, магическим действиям и включают лингвистические данные по каждому образу (происхождение, значение, параллели в других языках), отмечаются их распространённость в обрядах, в фольклоре и народном искусстве, что иллюстрируется подборкой мифологических текстов. Мифологические представления коми-пермяков активно фиксируются, однако описаны пока недостаточно. Подвергаясь значительной деформации, 
редукции и русификации, они тем не менее остаются и в наше время значимым элементом этнического культурного кода.

В разрабатываемом словаре будет учтен имеющийся опыт этнокультурного лексикографирования и предпринята попытка разноаспектного (включающего семантический, прагматический, ареальный параметры) словарного представления коми-пермяцкой мифологической лексики и фразеологии. Планируется также освещение ее этимологии и мотивированности в целом, описание особенностей современного функционирования описываемых мифологизмов.

В настоящей статье основное внимание обращено на характеристику лексико-фразеологического материала, который используется при формировании словаря, его состава. Словарь будет построен на описании различных классов мифологически отмеченной лексики и фразеологии - хрононимики (названий праздников, метеорологических и сакральных событий, значимых в хозяйственном, социальном и религиозном отношении); демонимов; терминов, обозначающих этапы, устойчивые ситуации, участников обрядов (родинного, свадебного, похоронно-поминального, календарных, хозяйственных, магических); названий обрядовой пищи, ритуальных предметов. Этот материал можно считать безэквивалентным, так как он маркирует специфичные для коми-пермяцкой этнической культуры реалии, хотя отдельные мифологически окрашенные номинации коми-пермяцкой духовной культуры заимствованы из русской народной культуры, созвучны образам и сюжетам культурных традиций других народов.

Значительное место в составе словаря будет отведено однословным и составным мифонимам. Мифологические персонажи до настоящего времени включены в бытовую и обрядовую сферы жизни носителей коми-пермяцкой культуры. Устойчивы табуистические запреты на упоминание банника (баняись) в бане («иначе угоришь, не вернёшься из бани»), «хозяина» подполья (джоджулісь) («иначе картофель будет портиться»), водяного (ваись) у воды, лешего (вӧрись) в лесу. Активность данной группы мифонимов подчеркивает тот факт, что мифологические персонажи различных локусов имеют разветвленные ряды номинаций. Так, водяные духи называются Водянӧй нылка, Ва бес, Куйим чуня тётка («ЫІжжыт юрын эм куйим чуня тётка. Йирыс - ӧддьӧн пылдын места речка вылас. Омут сэтӧн. Водянӧй нылка олӧ сэтӧн. Этадз тай шуӧныл. Эз менымм явитчылыл. Pblбакэзлӧ вӧлі явитчалӧм. петӧм, да эты кузя юрсиа пӧ котрасьныл 
пондӧм. Дерт, пӧди, абу бур одзын, умӧль одзын сія» - «В большом омуте есть тётка с тремя пальцами. Йир - очень глубокое место на речке. Омут там. Водяная девушка живёт там. Так говорят. Не показывалась [она] мне. Рыбакам показывалась она. Вышла [она], и с такими длинными волосами, мол, бегать стала. Конечно, наверное, не перед добром, перед плохим она [показывается]» - Мысы, Гайнский район). Именование водяного духа родственницей связано с табу (ср. русское диалектное тетка 'о лихорадке'). Эвфемическое название лешего Татшёмыс (букв. «такой-то») также используется как обереговое: «Татшӧмыс кыдз вӧрас петас, дак он тӧд, кыччӧ воштісьныl» - Мысы, Гайнский район («Леший-то как в лесу появится, то не знаешь, куда деваться»). В коми-пермяцкой демонимике отмечены заимствованные из русского языка (скорее всего, также для табуизации) обозначения духов природы и собственные названия: лешак, вор морт, вор дядь, киззя-виззя. Если именование дядь выступает как типичный случай задабривания духа причислением его к своим родственникам, то номинация киззя-виззя (букв. «пуговки в ряд») создана как переосмысление реального исторического факта. Владевшие обширными территориями коми края Строгановы вплоть до начала XX в. практически не допускали коми-пермяцких крестьян в лес ни на промысел, ни на разработку древесины, используя лесные угодья прежде всего для развития своих заводов (для охраны лесных массивов был учрежден большой штат лесных смотрителейобъездчиков). Переосмысление образа лесничего в лешего ощущается в массе описаний внешнего вида последнего. Так, в быличках о лешем «хозяин» показывается в четырехугольной красной шапке, на коне, в мундире: «Леший на белой лошади, грудь в ремнях, если покажется - это к беде, или пожар будет» (д. Васькова, Юрлинский район); «Случай был. Я пашу, а леший по полю идёт. У него пинжак, пуговки. Я не забоялся, по бороздке иду: «Куда ты, Еврей Евреевич?» Он говорит: «Вот, мужика ищу». Сам одет - пинжак, пуговки зеют, огнем горят» (Таволожанка, Юрлинский район). Относительно редко встречающееся у коми-пермяков название одного из лесных духов Ветряная мать («Старик... знал, видимо, он. Пришёл он, и спрашивает, у вас, мол, телёнок пропал? Потерялся, мол. Он сказал, надо, мол, сказать: Иван Иванович, Вэтрэная (Ветряная) Мать и Виктор Иванович, отпустите, мол, моего телёнка обратно...», д. Несоли, Косинский район). Название соотносится с отмеченными в свое время 
Куста Карьялайненом природными духами, известными также эстонцам, мордве, марийцам, чувашам (в чувашской сказке мать Ветра помогает обездоленным), венграм (у которых кроме Матери ветра также есть Дочь ветра, Сын ветра, Король ветра - персонажи, о которых нельзя плохо говорить) [10. С. 49].

В словаре будет представлено описание образных мотивов, сопутствующих тем или иным мифологическим персонажам: Лешак туй 'дорога лешего' (по суеверным представлениям, место в лесу, где легко заблудиться), Дюттян лешак 'качели лешего' (наклоненное дерево), Чача лешак 'игрушка лешего' (дерево с несколькими вершинками), Дом лешего (дупло на дереве), Костер лешего (по быличкам, леший любит греться у огня и часто разводит костры, которые при появлении людей отдаляются от них), Свадьба лешего (ураганный ветер, буря в лесу). Лингвистически такие мотивы представляют устойчивые сочетания, наделенные внутренней формой и представляющие мифологическое явление в действии, в пространственновременной конкретизации. Целесообразно включение в состав словаря мифологических слов и фразеологизмов, которые используются только как средство экспрессии. Таково название злого духа старинной дохристианской веры куль, закрепившееся в неодобрительных характеристиках дыш куль («ленивый черт»), нёштӧм куль («некрасивый черт»), мисьтӧм куль («немытый черт»), горзісь куль (букв. «плачущий черт» - бранно о громко плачущем). Название чёрта, дьявола Дяв, Дявыьв используется в высказываниях типа Дявыс тӧдӧ! («чёрт знает»): как и в современном русском языке, фразеологизмы с упоминанием нечистого духа выражают преимущественно отрицательные эмоции. Вторичная семантика мифонимов (характеристика человеческих недостатков, иррациональных ситуаций и пр.) так или иначе задается их первоначальным значением, мотивируется способностью мифонима в свернутом виде отражать миф.

Специфическое место в коми-пермяцкой культуре занимает категория «родителей» - наделенных сверхъестественными качествами недавно умерших членов семьи Важжес (Важжес рӧдительяс) (букв. «старые», «старые родители»), Виль важжез («новые старые»), которые считаются помощниками и покровителями конкретной семьи и обязательно поминаются в дни индивидуальных поминок на кладбище. Кроме них, коми-пермяки до сих пор поминают духов, называемых Важ важжез («древние старые», букв. «старые-престарые»). 
К ним причисляются первооснователи населенных пунктов, чудь, библейские персонажи, безвестные воины, погибшие в годы Гражданской войны: они, в отличие от покровителей семьи-родителей, рассматриваются не просто как помощники, а как мифологические предки, которым необходимо поклоняться. Свидетельство культа умерших - выражение Дзёбны кулӧмос 'похоронить умершего' (букв. «спрятать»; не просто предать погребению, а прибрать на место как нечто, составляющее ценность и в известное время могущее опять понадобиться).

Чрезвычайно специфичная и объемная часть мифологического словаря - хрононимы. Вслед за рядом исследователей, в частности О.В. Атрошенко, Ю.А. Кривощаповой, К.В. Осиповой [3], мы используем для обозначения общенародных и диалектных названий праздников, временных отрезков и «точек» календарного времени этот родовой термин вместо видового «геортоним». Геортонимы часто используются в функции хрононимов, и разведение этих понятий затрудняет особое, конкретное восприятие времени в народной культурной традиции: слабая отделенность его от события.

Словарь демонстрирует разнообразие названий собственных праздников коми-пермяков (Пикан лун, Пиканный день, праздник отражает особое отношение к траве-борщевику пикану - «поющей траве», из которой изготовлялись многоствольные дудки типа флейт; весенний поминальный праздник перед Троицей Пестера праздник название мотивировано обычаем приносить поминальную пищу в честь умерших родителей обязательно в плетеных заплечных корзинах из бересты). Кроме того, существуют свои названия и для усвоенных православных праздников. Так, праздник Троица называется и Тройча (Строииа), и Береза лун (букв. «День берёзы»), суббота перед Пасхой - Дюттян лун (букв. «День качелей»: «Весной-то тожно поминают, дюттян луныс бӧрын БІджыт лун; после дня качелей Великий день»). Последнее название ориентируется на обязательный атрибут, ключевой символ праздника, подчеркивает значимость качелей как способа символического перехода из одного мира в другой. Не случайно качели сооружались особым образом: неженатыми парнями, накануне Светлого Воскресенья, до наступления рассвета; веревка для них должна быть свита из новой пряжи. Любопытно, что ежегодно в отдельных странах Европы и сейчас отмечается международный день качания на качелях (4 августа: приурочен к окончанию лета) [11]. 
Следует отметить постепенное возвращение отдельных старых праздников типа Сарчик (Сарчик приносит весну - конец мая) с главным обрядовыми действиями ловить сарчика, хоронить сарчика. Птица сарчик (трясогузка, плишка) раньше других прилетает на север Пермского края и «приносит весну». Сарчик соответствует празднику трясогузки Вурщих Хатл у манси (букв. «день трясогузки»; приходится также на конец мая). По народной этимологии, слово сарчик восходит к царчик, в котором суффикс -чик уподобляет птицу маленькому царю. В реальности слово скорее всего является тюркским заимствованием, ср. татарское сыерчык 'скворец'. Птица воспринимается как воплощение души умершего, под трясогузками подразумевались предки, в облике птиц прилетавшие на родину. Считалось, что если на праздник пришло большое количество людей и много было угощений, то предки остались довольны и обеспечат хороший урожай.

Живы в современной традиции коми-пермяков праздники Турун вежан лун (День смены травы), Вӧл празник (Лошадиный праздник), местночтимый праздник (д. Урья, Кочевский район) Мӧс праздник (букв. «Коровий праздник» - приходится на Макарьев день, 7 августа: «Макарьяьс локтӧ эд ни, сія и эм Мӧс праздник, седьмого августа. Гуляйтісӧ, стряпайтісӧ, пивоесӧ керлісӧ, сурресӧ. Юрбитлісӧ, воллісӧ мӧд деревняись мый. Эстӧн Урьяас, ю вылӧ ся, ой быт юрбитасӧ, сэсся речка вылӧ лэдзчӧны асьяпоннас, суалӧны ваын» («Макарий подходит ведь уже, он и есть Коровий праздник, седьмого августа. Гуляли, стряпали, пиво делали. Молились, приходили и из других деревень. Здесь на Урье, на речку потом, всю ночь молятся, потом на речку идут утром, стоят в воде» - Урья, Кочевский район). Неясно, почему праздник в честь преподобного Макария Унженского был соотнесен с коровами, хотя день почитания этого животного у других европейских народов также приходится на разные сроки (у славян Коровьим праздником считается Власьев день, 24 февраля, в Баварии, Австрии и Швейцарии октябрь - время перегона коров с альпийских пастбищ) [12]).

Хрононимы нередко являются свидетельством древних культов и верований. Так, название Гаг лун (букв. «День червяка», праздник, отмечаемый в июне) отражает обычай задабривания-чествования огородного вредителя: «Гаг лунас эз садитлӧ» («В день червяка не садили [в огороде]»-Архипово, Кочевский район). Выражение сходно с названиями дней после теплой и дождливой Троицы типа отмеченных 
в русских говорах Прикамья хрононимов Мошкариная, Вшивая неделя [13. С. 176].

Отдельные праздники и связанные с ними обычаи ушли в прошлое. Так, единичные факты проведения обряда Инь вежан лун («День смены жены») фиксировались в 40-е гг. прошлого века (праздник отмечался в начале января, в ряде мест после Покрова, был особо почитаем среди жителей деревни Пыстогово Кочевского района). Мужчины из соседних деревень обменивались на срок до месяца своими женами (обычно в ходе святочных обрядовых бесчинств, но чаще в тех случаях, когда в семьях не рождались дети). Подобные реликтовые обычаи обменного брака, регулирующие семейную жизнь, известны и другим народам [14. С. 127-129].

В состав словаря будут включены мифологически окрашенные номинации из природного мира. Название божьей коровки Ен бабушка (ср. коми-зырянское бабыв, бабича 'бабочка') соотносится с русским диалектным бабка (Поволжье), где использовано не столько название старейшины рода, матери отцов и матерей, сколько известное многим мифологиям соотнесение бабочки с душой. Название «обусловлено представлением о переселении души умершего (бабушки) в насекомое» [15. С. 105], строится на отнесении насекомых к божьим, т.е. приближенным к Богу, существам (ср. сербохорватское божја о́вчица 'о божьей коровке', архангельское Божий коник 'кузнечик'). Мифологически осмысленные и в других традициях объекты природы в культуре коми-пермяков могут получить специфическое осмысление. Волшебное растение папоротник, например, воспринимается как наделенное демоническими свойствами: «Ӧддьӧн торкны мортьеэс папоротникнас. Иван лунас сія светитӧ. Ӧктылӧмась». («Людей очень портят папоротником. В Иванов день он цветет. Собирали» - Жемчужный, Гайнский район). Такое негативное восприятие травы известно и в других культурах (в некоторых уголках Англии уверены, что папоротник от дьявола, и называют его devil brush, devil's bush - «щетки, кусты дьявола») [16].

В словаре будут описаны номинации, отмечающие особенности коми-пермяцкой обрядовой практики. Обряд, как известно, разворачивается из мифа, является его инсценировкой (значения обрядовых действий заложены в мифе, хотя сами по себе могут и не осознаваться). Коми-пермяцкое выражение Кӧч кутны (букв. «зайца поймать») используется в значении 'закончить косить участок луга последним' и 
совпадает с русской обрядовой игрой «ловить зайчика» (архангельское) - остатком древнего обряда дожинок («Когда остается последний нескошенный участок, говорили: «Девки, имайте зайчика»; кто последний раз «коснет», тот поймал» - Азаполье, Мезенский р-н, Архангельская область) [17]. В европейской народной традиции заяц также известен как один из духов, олицетворяющих плодородие (чаще под образом зайца скрывался хлебный дух, ср. немецкое Hase как одно из названий последнего снопа [18. С. 446], архангельское зайка 'последний несжатый колосок').

Для отдельных культурных комплексов характерно обилие заимствованных форм. Так, восприятие из русской традиции деталей свадебного обряда привело к усвоению терминов типа чолпан новйотны ('благословлять молодых хлебом - о родителях', букв. «носить каравай»; сакральность свадебного хлеба подчеркивает название каравая челпан, которое, как считается, является славянским и этимологически связано с чело). К полукалькам относятся терминологические глагольные сочетания типа обедайттон ветлотны (букв. «обедая, ходить»; аналог пермского диалектного обрядового термина ходить по обедам - о прощальном обходе невестой с подружками перед свадьбой своей родни; сочетание подчеркивает особую значимость в традиции родовых связей). Выражение знамьё сетны (букв. «дать задаток-знак») связано с вручением подарка жениху в знак согласия выйти за него замуж. «Знаменем» могли быть головной платок, который невеста повязывала на руку жениху, расшитое полотенце. Повязывание «знамени» (именно этот платок надевали невесте после снятия венка и заплетания бабьей косы) осмыслялось как символическое скрепление союза молодых. Немало заимствований и в похоронной терминологии. Оборот-полукалька Дари уднь 'причастить, напоить перед смертью святой водой' (букв. «угостить дарами») содержит русское дары, которым называется причастие (обычно дары, или Божьи дары, представляют вино, напиток с кусочками просфоры, символ плоти и крови Иисуса Христа).

Отражающие христианскую обрядность праздники, рассказы о сверхъестественных существах и событиях насыщены деталями, которые свидетельствуют о сохранении у коми-пермяков традиционных (языческих в своей основе) верований. «Коми-пермяки по сути трансформировали христианство, изменив его содержание и форму. Христианство коми-пермяков - это политеистическое язычество с 
вкраплениями христианской обрядовой традиции» [19. С. 187]. Проклятье, пожелание кары в загробном мире Калёнӧй стӧббес куталны (букв. «калёные столбы хватать» («...зоныслӧ шуӧма, понан пӧ калёнӧй стӧббесӧ куталны» - «...Сыну сказала, будешь, дескать, калёные столбы хватать» - Коса, Косинский район) строится на устойчивой идее очистительного адского огня и содержит указание на атрибуты ада, на идею возмездия на том свете за грехи. По материалам А.Н. Соболева [20. С. 174-185], по текстам народных духовных стихов грешника в аду ждут одр огненный, столь огненные, котль, вертела, клещи, каленая сковорода, каленые угли, каленые плиты, раскаленные столбы. Еще один образ того света отражен в комипермяцком бранном выкрике Мун вакрамеш, где, очевидно, содержится посыл в ад (кромешный ад). Искусственное вакрамеж образовано от русского крома «край» и ва коми «вода», следовательно, содержит идею разделяющей тот и этот свет реки (в мифологии комизырян известной как сир ю «смоляная река», сир биа ю «смоляного огня река», пӧсь ю «горячая река»). Огонь, огненная река наделялись очистительной силой и самостоятельно представляли тот свет: «Умрешь, надо огненную-то реку перейти. Если сможешь, все, в реку пойдешь, если нет - в ад будешь. Как перейти, то и говорят, надо много одежды не давать покойнику-то. Некоторые ведь много ложат да че. Говорят, и легко одевать, чтобы он мог идти, и пускают еще ниточку. Вот по этой ниточке, говорят, он и переходит огненную реку-то. Грехи переносит» (Гавино, Юсьвинский район). Образ огненной реки, а также огненного озера отмечен и в ряде других мифологий, в частности, по древнеиранским представлениям, душа грешника после суда срывается с моста и падает в огненную реку [21].

Мифологические коннотации, таким образом, свойственны разным тематическим группам лексики и фразеологии коми-пермяцкого языка. Очевидны самобытность, этническая окрашенность мифонимов, содержащих представления коми-пермяков о жизни, смерти, времени, о природе и ее стихийных силах. Она проявляется в связи названий обрядовых персонажей, атрибутов и акций с древними финноугорскими культами птиц, животных, растений. Оригинальными становятся в коми-пермяцкой культурно-языковой среде и многие заимствованные мифонимы, проходя своеобразную переработку в стихии народной коми-пермяцкой речи: одновременно с языковыми преобра- 
зованиями в них меняется и содержательная сторона. Православные религиозные представления у коми-пермяков, как и собственные, восходящие к язычеству, наделяются умилостивительным, предохранительным и продуцирующим смыслом, актуализируют тему поклонения умершим предкам, которые символизируют единство рода и наделяются свойствами божества. Словарное описание позволит в компактной форме представить архаические слои коми-пермяцкой народной культуры, отразить закрепленные в национальносамобытной лексике и фразеологии особенности этнического сознания и мировосприятия.

\section{Литература}

1. Якобсон Р.О. Лингвистика в ее отношении к другим наукам // Якобсон Р.О. Избранные работы. М., 1985. С. 369-420.

2. Русинова И.И. Проблема лексикографического описания лексических и фразеологических единиц семантической сферы «Народная магия» (по данным говоров и мифологических рассказов Пермского края) // Вестник Пермского университета. Российская и зарубежная филология. 2012. № 4. С. 15-21.

3. Атрошенко О.В., Кривощапова Ю.А., Осипова К.В. Русский народный календарь. М. : АСТ-Пресс Книга, 2015. 544 с.

4. Мироненко И.Ю. Смертный узел: материалы к этнолингвистическому словарю донского казачества // Проблемы истории, филологии, культуры. 2011. № 3. C. $129-132$.

5. Салимов Ф.И., Салимов Р.Ф. Электронный этнолингвистический терминологический словарь татарского языка. Казань, 2014. URL: http://ethnoling.antat.ru (дата обращения: 10.09.2017).

6. Хисамитдинова Ф.Г. Мифологический словарь башкирского языка. М. : Наука, 2010. 452 c.

7. Корепина Л.Ф. Лексикографическая разработка мифологического ономастикона для младших школьников // Вестник Псковского государственного университета. Серия: Социально-гуманитарные науки. 2011. С. 183-187.

8. Красных В.В. Основные проблемы описания словаря и грамматики лингвокультуры (психолингвокультурологический подход) // Проблемы истории, филологии, культуры. 2014. № 3 (45). С. 19-22.

9. Мифология коми. URL: http://www.komisc.ru/illi/folk/myth/2.htm (дата обращения: 05.09.2017).

10. Карьялайнен К.Ф. Религия югорских народов / пер. с нем. Н.В. Лукиной. Томск : Изд-во Том. ун-та, 1996. 264 с.

11. День качания на качелях. URL: http://eko-jizn.ru/?p=15288 (дата обращения: 27.01.2018).

12. Борн Ольга. Коровий праздник. URL: http://www.russianwomanjournal.com/ culture3/102161011.htm (дата обращения: 27.01.2018). 
13. Черных A.B. Русский народный календарь в Прикамье. Пермь : Пушка, 2006. Ч. $1.368 \mathrm{c}$.

14. Коломиеи О.П. Архаичные формы брака у чукчей в XIX - начале XX века. // Вестник Томского государственного педагогического университета. 2012. № 1. C. $127-129$.

15. Мельничук О.С., Білодід I.К., Коломіеиь В.Т. и др. Етимологічний словник украінской мови. Киів: Наук. думка, 1982. Т. 1. 631 с.

16. Мифология / Папоротник. URL: http://www.a700.ru/plants/149paporotnik.html (дата обращения: 27.01.2018).

17. Энииклопедия «Азаполье». URL: http://1553.ru/projects/azap/page62.htm (дата обращения: 27.01.2018).

18. Фрэзер Д.Д. Золотая ветвь: исследование магии и религии. М. : Политиздат, 1980. 832 с.

19. Головчанский Г.П. К вопросу о завершенности процесса христианизации коми-пермяков // Труды Камской археолого-этнографической экспедиции. 2009. Вып. 6. С. 182-189.

20. Соболев А.Н. Загробный мир по древнерусским представлениям. Сергиев Посад, 1913. $207 \mathrm{c}$.

21. Грайф Петер. Ад // Simbolarium. URL: http://www.simbolarium.ru/ simbolarium/sym-uk-cyr/cyr-a/ag/ad.htm (дата обращения: 27.01.2018).

\section{THE KOMI-PERMYAK MYTHOLOGICAL LEXIS AND PHRASEOLOGY AS} AN OBJECT OF LEXICOGRAPHIC DESCRIPTION

Voprosy leksikografii - Russian Journal of Lexicography, 2018, 14, pp. 107-121.

DOI: $10.17223 / 22274200 / 14 / 6$

Ivan A. Podyukov, Perm State Humanitarian Pedagogical University (Perm, Russian Federation). E-mail: podjukov@yandex.ru

Keywords: mythological and ritual lexis and phraseology, cultural borrowings, dictionary, Komi-Permyak language.

* The study was supported by the Russian Foundation for the Humanities (Project No. 17-14-59001).

The article presents a description of different groups of Komi-Permyak mythological vocabulary and phraseology: nominations of mythological characters and events, mythologised natural phenomena, names of ritual attributes and actions. The corpus of mythologically coloured names and statements, preserved in the language as an element of the archaic tradition, enables to consider the characteristics of Komi-Permyaks' ethnic mentality for their mythological concepts are still a significant element of the ethnic cultural code. The corpus includes original as well as borrowed (first of all, from the Russian language) mythonyms, which underwent language processing in the KomiPermyak folk speech.

This article thoroughly considers different groups of mythologically coloured vocabulary and phraseology: folk chrononyms; demonyms; ritual terms that indicate stages, situations, participants of birth, wedding, funeral and commemorative, calendar, household, magic rites; names of ritual food and objects; names of symbolic ritual ac- 
tions. The names of holidays, in particular, quite often serve as evidence of of the ancient Finno-Ugrian cults of birds, animals, plants (Pikan Day, a holiday at the end of summer connected with a special attitude to the cow-parsnip plant pikan - "singing grass"; Pester holiday, a commemorative day before the Trinity Sunday, when some funeral food in over-the-shoulder birch-bark wicker baskets is brought to graves to commemorate the deceased parents; the Trinity Sunday; the Swing Day, a Saturday before the Easter). The loss of some folk holidays (such as the Wife's Change Holiday) and attempts to revive old holidays such as the Sarchik, the Wagtail Day (at the end of May), the Day of the Grass Change, the Horse Holiday, the Cow Holiday are illustrated in detail by the conversational contexts.

Rite terminology vividly demonstrates the close relation of a rite and a myth, the development of a rite from a myth. For example, a Komi-Permyak phrase Kyoch kutny (literally "to catch a hare") is used in the meaning "to be last to finish mowing a hay field', which coincides with the Russian ritual game "to catch a leveret" (Arkhangelsk) and is played at the end of field work. Like in some European folk traditions, one of the spirits personifying earth fertility hides behind the "hare" in this phrase. In describing Biblical expressions that entered the Komi-Permyak language during the adoption of the Christian tradition, following a number of studies, combinations of these Biblical expressions with cultural forms going back to polytheistic paganism, typical of the Komi-Permyaks, is mentioned. Orthodox religious beliefs of the Komi-Permyaks, like their own, are endowed with propitiatory, preventive and productive meanings; they actualise the topic of the worship of the deceased forefathers who symbolise the unity of the clan and are endued with the qualities of a god. The lexico-phraseological material presented in the dictionary is generally non-equivalent; it marks realia specific for the Komi-Permyak ethnic culture. At the same time, particular mythologically coloured nominations of the Komi-Permyak spiritual culture are accordant to the images and plots of other peoples' cultural traditions.

The suggested ehnolinguistic description of the least documented Finno-Ugrian languages provides insight into how spiritual culture is reflected in the language, and into the cultural-linguistic links of the Komi-Permyaks with the other nationalities of the Kama River region.

\section{References}

1. Jacobson, R.O. (1985) Izbrannye raboty [Selected works]. Moscow: Progress. pp. 369-420.

2. Rusinova, I.I. (2012) The problem of lexicographic description of lexical and phraseological units of the semantic field "folk magic" (on the data of the dialects and mythological stories of the Perm Krai). Vestnik Permskogo universiteta. Rossiyskaya $i$ zarubezhnaya filologiya - Perm University Herald. Russian and Foreign Philology. 4. pp. 15-21. (In Russian).

3. Atroshenko, O.V., Krivoshchapova, Yu.A. \& Osipova, K.V. (2015) Russkiy narodnyy kalendar' [Russian folk calendar]. Moscow: AST-Press Kniga.

4. Mironenko, I.Yu. (2011) "Mortal knot": material for the ethno-linguistic dictionary of the Don Cossacks. Problemy istorii, filologii, kul'tury - Journal of Historical, Philological and Cultural Studies. 3. pp. 129-132. (In Russian). 
5. Salimov, F.I. \& Salimov, R.F. (2014) Elektronnyy etnolingvisticheskiy terminologicheskiy slovar' tatarskogo yazyka [Electronic ethnolinguistic terminological dictionary of the Tatar language]. Kazan. [Online]. Available from: http://ethnoling.antat.ru. (Accessed: 10.09.2017).

6. Khisamitdinova, F.G. (2010) Mifologicheskiy slovar' bashkirskogo yazyka [The mythological dictionary of the Bashkir language]. Moscow: Nauka.

7. Korepina, L.F. (2011) Lexicographical formulation of mythological onomasticon for pupils. Vestnik Pskovskogo gosudarstvennogo universiteta. Seriya: Sotsial'nogumanitarnye nauki - Vestnik PskovSU. Series "Socially-Humanitarian and PsychoPedagogical Science”. pp. 183-187. (In Russian).

8. Krasnykh, V.V. (2014) Main problems of linguistic culture vocabulary and description of grammar (psychological, linguistic and culturological approach). Problemy istorii, filologii, kul'tury - Journal of Historical, Philological and Cultural Studies. 3 (45). pp. 19-22. (In Russian).

9. Komisc.ru. (n.d.) Mifologiya komi [Mythology of the Komi]. [Online]. Available from: http://www.komisc.ru/illi/folk/myth/2.htm. (Accessed: 05.09.2017).

10. Kar'yalaynen, K.F. (1996) Religiya yugorskikh narodov [Religion of the Ugra peoples]. Translated from German by N.V. Lukina. Tomsk: Tomsk State University.

11. Eko-jizn.ru. (n.d.) Den' kachaniya na kachelyakh [The Swing Day]. [Online]. Available from: http://eko-jizn.ru/?p=15288. (Accessed: 27.01.2018).

12. Born, O. (2011) Koroviy prazdnik [The Cow Holiday]. [Online]. Available from: http://www.russianwomanjournal.com/culture3/102161011.htm. (Accessed: 27.01.2018).

13. Chernykh, A.V. (2006) Russkiy narodnyy kalendar'v Prikam'e [Russian folk calendar in the Kama region]. Pt. 1. Perm: Pushka.

14. Kolomiets, O.P. (2012) Arkhaichnye formy braka u chukchey v XIX - nachale XX veka. // Vestnik Tomskogo gosudarstvennogo pedagogicheskogo universiteta Tomsk State Pedagogical University Bulletin. 1. pp. 127-129.

15. Mel'nichuk, O.S. et. al (1982) Etimologichniy slovnik ukrainskoy movi [Etymological dictionary of Ukrainian]. Vol. 1. Kiev: Nauk. dumka.

16. Mythology. (n.d.) Paporotnik [Fern]. [Online]. Available from: http://www.a700.ru/plants/149-paporotnik.html. (Accessed: 27.01.2018).

17. Encyclopedia “Azapolie”. (n.d.) Senokos [Hay time]. [Online]. Available from: http://1553.ru/projects/azap/page62.htm. (Accessed: 27.01.2018).

18. Frezer, D.D. (1980) Zolotaya vetv': issledovanie magii i religii [Golden branch: a study of magic and religion]. Moscow: Politizdat.

19. Golovchanskiy, G.P. (2009) K voprosu o zavershennosti protsessa khristianizatsii komi-permyakov [On the completion of the Christianization process of the KomiPermyaks]. Trudy Kamskoy arkheologo-etnograficheskoy ekspeditsii. 6. pp. 182-189.

20. Sobolev, A.N. (1913) Zagrobnyy mir po drevnerusskim predstavleniyam [The Underworld according to Old Russian ideas]. Sergiev Posad: Tip. Vil'de.

21. Grayf, P. (n.d.) Ad [Hell]. [Online]. Available from: http://www.simbolarium.ru/simbolarium/sym-uk-cyr/cyr-a/ag/ad.htm. (Accessed: 27.01.2018). 